\title{
DESEMPENHO REPRODUTIVO DE FÊMEAS DE JUNDIÁ ALIMENTADAS COM DIFERENTES FONTES PROTÉICAS
}

\author{
REPRODUCTIVE PERFORMANCE OF JUNDIÁ FEMALES FED WITH DIFFERENT \\ PROTEIN SOURCES
}

\author{
Parra, J.E.G. ${ }^{1}$, Radünz Neto, J. ${ }^{2}$, Veiverberg, C.A. ${ }^{2}$, Lazzari, R. ${ }^{2,3 *}$, Bergamin, G.T. ${ }^{2}$, \\ Corrêia, V. ${ }^{2}$, Ferreira, C.C. ${ }^{2}$ e Ferreira, F.W. ${ }^{4}$
}

\begin{abstract}
${ }^{1}$ Universidade Regional Integrada do Alto Uruguai e das Missões. CEP 97700-000. Campus de Santiago, RS. Brasil. parra@urisantiago.br

${ }^{2}$ Laboratório de Piscicultura. Departamento de Zootecnia. Universidade Federal de Santa Maria. CEP 97105900. Santa Maria, RS. Brasil.

${ }^{3}$ Centro Federal de Educação Tecnológica de Bento Gonçalves. CEP 98590-000. Unidade Descentralizada de Ensino de Santo Augusto, RS. Brasil. *rlazzari@cefetbg.gov.br

${ }^{4}$ Departamento de Biologia e Química. Universidade Regional do Noroeste do Estado do Rio Grande do Sul. CEP 98700-000. ljuí, RS. Brasil. piscis@unijui.edu.br
\end{abstract}

\section{PalaVRas chaVe adicionais}

Farelo de soja. Farinha de peixe. Farinha de carne. Farinha de ossos. Nutrição de reprodutores. Rhamdia quelen.

\section{RESUMO}

Dois experimentos foram conduzidos para avaliar o desempenho reprodutivo de fêmeas de jundiá alimentadas durante 71 dias com diferentes fontes protéicas. No experimento 1 , foi avaliado o farelo de soja associado à farinha de carne e ossos (CS), levedura (LS) ou farinha de peixe (PS). No segundo experimento avaliaram-se os níveis de 0,35 e $70 \%$ de substituição da farinha de carne e ossos da dieta CS do experimento 1 por farelo de soja (CS0, CS35 e CS70, respectivamente). As fêmeas foram induzidas à desova utilizando-se extrato hipofisário de carpa. No experimento 1 , o diâmetro do saco vitelino foi maior nos ovos das matrizes alimentadas com as dietas CS e PS. No experimento 2, o desenvolvimento embrionário, vitelínico e larval foi superior no tratamento CSO. Conclui-se que a utilização de farinha de carne e ossos e farelo de soja como fontes protéicas apresentam-se como boa opção na alimentação de fêmeas reprodutoras de jundiá.

\section{SUMMARY}

Two trials were carried out to evaluate the

Recibido: 23-6-08. Aceptado: 22-10-08.

\section{ADDITIONAL KEYWORDS}

Soybean meal. Fish meal. Meat meal. Bone meal. Broodstock nutrition. Rhamdia quelen.

reproductive performance of jundiá females fed during 71 days with different protein sources. In the first trial soybean meal was associated to meat and bone meal (CS), sugar cane yeast (LS) and fish meal (PS). In the second trial the effect of replacement of meat and bone meal by soybean meal was evaluated to the levels 0,35 and $70 \%$ of the CS diet (CS0, CS35 e CS70, respectively). The spawning of females were induced with carp hypophysis extract. In the trial 1 , embryonic development was higher in the eggs from females fed CS and PS. In the trial 2, embryonic, vitelinic and larval development were higher in CSO treatment. This concluded that meat and bone meal and soybean meal used as protein sources showed good option in the feeding of reproductive jundiá females.

\section{INTRODUÇÃO}

A qualidade da desova dos peixes é um ponto importante na expansão da aquacultura, seja de espécies marinhas ou de água doce. Para piscicultura comercial, uma desova de 
boa qualidade é aquela que resulta em altas taxas de fertilização, eclosão e sobrevivência após a absorção do saco vitelino (Bromage et al., 1992). Entretanto, estes não são os únicos fatores que determinam a qualidade da desova. As medidas morfométricas das larvas e pós-larvas têm sido usadas como indicadoras da qualidade de gametas em algumas espécies de peixes (Kjorsvik, 1994).

Os nutrientes da dieta influenciam o desempenho reprodutivo de várias espécies de peixes, como truta arco-íris (Pereira et al., 1998), tilápia (Gunasekera et al., 1996a) e bagres do gênero Clarias (Adewumi, 2006). Entre os componentes da dieta, a proteína é um fator importante por ser constituinte dos organismos animais em todas as fases de vida, além de estar relacionada à formação de enzimas e hormônios (Pezzato, 1995). Na embriogênese, a proteína é fonte de aminoácidos essenciais que estão envolvidos nas principais atividades de síntese nos estágios iniciais de desenvolvimento. Além disso, as proteínas estão presentes nos ovos de peixes como lipoproteínas, hormônios e enzimas, determinando a qualidade do ovo e a produção de peixes em larga escala (Brooks etal., 1997).

A elaboração de dietas adequadas nutricionalmente para os reprodutores está relacionada com o tipo, qualidade e composição dos ingredientes utilizados na formulação. O tipo de ingrediente e seu nível de inclusão na dieta influenciarão na composição da mesma, bem como em sua apresentação e aceitação pelo peixe (Campabadal e Celis, 1996). Fatores como estes são responsáveis por determinar o crescimento e desenvolvimento gonadal dos peixes, garantido assim o sucesso reprodutivo.

Uma grande variedade de fontes protéicas têm sido avaliadas na nutrição de peixes. A farinha de peixe é a fonte protéica mais utilizada mundialmente, devido à composição de aminoácidos e boa palatabilidade (Mohsen e Lovell, 1990), apesar de ser um ingrediente de elevado custo (Kim et al., 1997). A farinha de carne e ossos é uma importante fonte protéica de origem animal, que apresenta boa palatabilidade, altos níveis de cálcio e fósforo e bom equilíbrio de aminoácidos essenciais, principalmente metionina e cistina (Pezzato, 1996). A levedura de cana (Saccharomyces cerevisiae) é um ingrediente com teor protéico que varia de 37 até $45 \%$ de proteína bruta (PB), e apresenta bons resultados no crescimento de larvas e juvenis de jundiá (Piaia e Radünz Neto, 1997; Coldebella e Radünz Neto, 2002). O farelo de soja é a fonte de origem vegetal considerada de melhor composição (Lovell, 1988) e o ingrediente mais estudado pela sua disponibilidade e homogeneidade de composição (Pezzato, 1995).

O jundiá (Rhamdia quelen) é uma espécie encontrada desde o sudeste do México até o centro da Argentina (Baldisserotto, 2004). É muito apreciado para o consumo na Argentina, Brasil e Uruguai, tendo grande importância comercial (Salhi et al., 2004). É adaptado a diferentes ambientes, apresenta bom crescimento e boas características para processamento (Carneiro, 2004). Diversas fontes protéicas têm sido avaliadas para pós-larvas e juvenis de jundiá, apresentando resultados diferenciados em relação à fase de vida (Lazzari et al., 2007; Piaia et al., 1997; Coldebella e Radünz Neto, 2002). Para reprodutores de jundiá, entretanto, estes dados são inexistentes.

O objetivo do presente estudo foi avaliar as respostas reprodutivas de fêmeas de jundiá alimentadas com diferentes fontes protéicas.

\section{MATERIALE MÉTODOS}

Este trabalho foi desenvolvido no Laboratório de Piscicultura da Universidade Federal de Santa Maria-RS. Foram conduzidos dois experimentos, realizados de julho a outubro de 2005 (experimento 1) e fevereiro a maio de 2006 (experimento 2). Cada experimento foi dividido em três fases: fase I: alimentação dos reprodutores; fase II: reprodução induzida e incubação de ovos e 


\section{FONTES PROTÉICAS E DESEMPENHO REPRODUTIVO DE FÊMEAS DE JUNDIÁ}

larvas; fase III: larvicultura.

Para a fase I, 12 fêmeas de jundiá foram distribuídas em três tanques-rede $\left(1 \mathrm{~m}^{3}\right)$ instalados em um viveiro de terra $\left(900 \mathrm{~m}^{2}\right)$. No mesmo viveiro, um tanque-rede $\left(4 \mathrm{~m}^{3}\right)$ foi instalado para acondicionar os machos. Nos dois experimentos foram utilizadas fêmeas com peso aproximado de $700 \mathrm{~g}$, que receberam as dietas experimentais durante dez semanas. A alimentação foi fornecida uma vez ao dia (17 horas), na proporção de $2 \%$ da biomassa. Os machos foram alimentados até a saciedade aparente com dieta comercial (extrusada, $28 \%$ de proteína) durante o mesmo período.

No experimento 1 foram avaliadas três dietas, formuladas com diferentes fontes protéicas: CS (farinha de carne e ossos e farelo de soja), PS (farinha de peixe e farelo de soja) e LS (levedura de cana e farelo de soja). No segundo trabalho, foi feita a substituição parcial da farinha de carne e ossos por farelo de soja, em níveis de $35 \%$ (CS35) e 70\% (CS70), além da dieta controle, sem substituição (CS0). A composição das dietas encontra-se na tabela I.

Tabela I. Composição das dietas experimentais (\%). (Composition of experimental diets (\%)).

\begin{tabular}{|c|c|c|c|c|c|c|}
\hline & \multicolumn{3}{|c|}{ Experimento 1} & \multicolumn{3}{|c|}{ Experimento 2} \\
\hline & CS & PS & LS & CSO & CS35 & CS70 \\
\hline Farinha de carne e ossos & 32 & - & - & 36 & 23,4 & 10,8 \\
\hline Farinha de peixe & - & 27 & - & - & - & - \\
\hline Levedura de cana & - & - & 34 & - & - & - \\
\hline Farelo de soja & 31 & 30 & 37 & 35 & 47,6 & 60,2 \\
\hline Farelo de trigo & 17 & 17,98 & 7,98 & 15 & 15 & 15 \\
\hline Milho & 8,98 & 14 & 10 & 5,98 & 5,98 & 5,98 \\
\hline Óleo de canola & 8 & 8 & 8 & 5 & 5 & 5 \\
\hline Fosfato bicálcico & 1 & 1 & 1 & 1 & 1 & 1 \\
\hline Sal & 1 & 1 & 1 & 1 & 1 & 1 \\
\hline Vitaminas e minerais $^{1}$ & 1 & 1 & 1 & 1 & 1 & 1 \\
\hline Antioxidante ${ }^{2}$ & 0,02 & \multicolumn{4}{|c|}{ Composição analisada } & 0,02 \\
\hline Proteína bruta & 37,7 & 35,0 & 36,3 & 33,5 & 32,6 & 31,7 \\
\hline Matéria mineral & 14,5 & 13,3 & 6,3 & 14,1 & 12,2 & 9,5 \\
\hline Extrato etéreo & 14,1 & 15,0 & 10,5 & 10,5 & 10,3 & 8,9 \\
\hline Umidade & 7,2 & 7,6 & 7,2 & 6,4 & 7,2 & 6,7 \\
\hline Extrativos não nitrogenados & 26,5 & 29,2 & 39,8 & 31,2 & 33,5 & 38,9 \\
\hline Energia digestível $(\mathrm{kcal} / \mathrm{kg})^{3}$ & 3635 & 3650 & 3591 & 3245 & 3244 & 3218 \\
\hline
\end{tabular}

Tratamentos experimento 1: CS= Farinha de carne e ossos + farelo de soja; PS= Farinha de peixe + farelo de soja; LS= Levedura de cana + farelo de soja. Tratamentos experimento 2: CS0= Farinha de carne e ossos $(F C O)$ + farelo de soja (FS); CS35= 35 \% de substituição da FCO por FS do tratamento CS0; CS70 $=70 \%$ de substituição da FCO por FS do tratamento CSO.

${ }^{1}$ Composição da mistura vitamínica e mineral (por kg de produto) Ac. fólico 400 mg, Ác. nicotínico 14000 mg, Ác. pantotênico: 8000 mg, Cobalto: 1500 mg, Cobre: 1500 mg, Colina: 1500 mg, Ferro: 50000 mg, lodo: 700 mg, Manganês: 23000 mg, Selênio: 250 mg, Vit. A: 6000000 UI, Vit. B1: 1400 mg, Vit. B2: 3375 mg, Vit. B6: 4830 mg, Vit. B12: $5000 \mu$ g, Vit. C: 25000 mg, Vit. D3: 53000 UI, Vit. E: 22500 mg, Vit. K3: 5000 mg, Zinco: $40000 \mathrm{mg}$.

${ }^{2}$ Antioxidante: $32 \%$ etoxiquina, $18 \%$ propil-galato, $50 \%$ veículo-talco.

${ }^{3}$ Calculada-ED $=[(\mathrm{PB} \times 5,64 \times 0,84)+(\mathrm{Eex9}, 44 \times 0,9)+(\mathrm{ENN} \times 4,11 \times 0,60)] / 100$ (Robinson e Li, 2002). 
Na primeira, quarta e décima semanas experimentais foram realizadas medições de peso $(\mathrm{g})$, além do cálculo de ganho em peso $(\mathrm{GP}=$ peso final - peso inicial, em $\mathrm{g}$ ) e fator de condição $\left(\mathrm{FC}=\right.$ peso/comprimento total $\left.{ }^{3}\right)$ das fêmeas. Essas biometrias serviram para ajuste do fornecimento de ração e avaliação do crescimento e desenvolvimento reprodutivo, por avaliação das características externas (ventre abaulado, papila genital avermelhada e intumescida) (Silva et al., 2004).

Para a fase II, de cada tanque-rede foram utilizadas quatro fêmeas para indução à desova e uma para coleta de ovócitos. $\mathrm{Na}$ indução da desova utilizou-se extrato hipofisário de carpa ( $4 \mathrm{mg} / \mathrm{kg}$ para as fêmeas e $2 \mathrm{mg} / \mathrm{kg}$ para os machos) em dose única, aplicado na cavidade abdominal, junto à base da nadadeira peitoral (Silva et al., 2004). Um macho e uma fêmea foram colocados em uma incubadora de fibra de vidro (tipo Zoug, 60 1), onde a desova ocorreu naturalmente. Após a desova, os casais foram retirados das incubadoras, permanecendo a massa de ovos fertilizados para completar o desenvolvimento embrionário e eclosão.

De uma fêmea de cada tanque-rede foi coletada uma amostra de ovócitos não fecundados, usando uma cânula intraovariana. Além disso, uma amostra de $5 \mathrm{ml}$ de ovos hidratados foi coletada de cada incubadora após 12 horas de desova. A partir desta amostra, foi verificada a taxa de fecundação (\% de ovos fecundados). Os ovos e ovócitos foram fixados em formol neutro a 4\% (Eiras et al., 2000), microfotografados e medidos em estereoscópiomicroscópio Leica M2125. Para a análise morfométrica das imagens foi utilizado um analisador de imagens acoplado ao programa Somnium 1.0 SMN.

Ainda na fase II, amostras de no mínimo 10 larvas foram coletadas de cada incubadora às 12, 24, 36 e 48 horas após a eclosão, para medidas de comprimento e área da larva e área de saco vitelino. A fixação e análise destas amostras seguiram o mesmo procedimento que para os ovos e ovócitos.

Para a fase III, quarenta e oito horas depois da eclosão foram coletadas três amostras de 160 larvas de cada incubadora e estocadas em unidades de criação (30 larvas/l) de um sistema de recirculação de água. Uma dieta foi preparada com os seguintes ingredientes: fígado bovino $(30 \%)$, levedura de cana $(57 \%)$, lecitina de soja $(2 \%)$, farelo de arroz desengordurado $(8 \%)$ e mistura vitamínica e mineral (3\%). Esta dieta foi fornecida às pós-larvas durante 14 dias, em seis alimentações diárias (das 8 às 18 horas).

No momento da estocagem das larvas no sistema de criação, dez pós-larvas de cada tratamento foram retiradas para amostragem inicial. Aos 7 e 14 dias de criação, realizou-se a contagem das pós-larvas das unidades experimentais para avaliação da sobrevivência, e dez animais de cada repetição foram coletados para biometria. Após as medidas de peso e comprimento total, as pós-larvas foram fixadas em formol neutro (4\%) para posterior medição da área da pós-larva (APL, mm²). A taxa de crescimento específico (TCE, \%/dia) foi calculada pela fórmula: ((ln peso final - ln peso inicial)/dias de experimento) $* 100$.

Os dados foram submetidos ao teste de normalidade, sendo depois analisados por análise de variância. No experimento II os dados zootécnicos foram ajustados em função do peso inicial das fêmeas, visto que este foi diferente entre os tratamentos. Os testes de comparação de médias utilizados foram teste de Tukey para o experimento I, teste Pdiff para as dados zootécnicos do experimento II (ajustados para o peso inicial) e teste $t$ para as demais variáveis do experimento II, todos a nível de $5 \%$ de significância. Todas as análises foram realizadas com o software SAS (1997).

\section{RESULTADOSEDISCUSSÃO}

No experimento 1 as fêmeas de jundiá apresentaram diferenças significativas de 


\section{FONTES PROTÉICAS E DESEMPENHO REPRODUTIVO DE FÊMEAS DE JUNDIÁ}

desempenho ao final de 10 semanas de alimentação. O tratamento CS apresentou os melhores resultados de ganho em peso e peso final em comparação com LS, mas não diferiu significativamente do tratamento PS (tabela II). No experimento 2 não foram observadas diferenças entre os tratamentos, para os valores ajustados em função do peso inicial (tabela II).

A utilização de fontes protéicas para o jundiá tem sido direcionada principalmente para as fases de larvicultura e alevinagem. Levedura de cana e fígado bovino cru são excelentes fontes protéicas para o desenvolvimento inicial das larvas de jundiá (Piaia et al., 1997). Juvenis de jundiá alimentados com levedura de cana e farelo de soja apresentaram desempenho superior a dietas com farelo de soja e farinha de carne e ossos, e levedura de cana e farinha de carne e ossos (Coldebella e Radünz Neto, 2002). A combinação de farinha de carne e ossos ou farinha de peixe com farelo de soja resultam em bom crescimento para juvenis de jundiá (Lazzari et al., 2007). Todavia para a fase de reprodução, não temos conhecimento de trabalhos desenvolvidos com esta espécie.

No experimento 1, a desova das fêmeas se deu nas seguintes proporções: do tratamento CS desovaram 4 fêmeas, $(100 \%$ do total de fêmeas induzidas); do tratamento PS desovaram $2(50 \%)$ e do tratamento LS apenas uma fêmea desovou (25\%). No experimento 2, as fêmeas alimentadas com a dieta CS70 não apresentaram sucesso na desova. Uma fêmea chegou a liberar óvulos por extrusão, mas às 12 horas após a desova todos os ovos estavam mortos e foram descartados. Somente uma das fêmeas alimentadas com a dieta CS35 desovou livremente, e das fêmeas induzidas no tratamento CSO, somente duas desovaram.

As fêmeas alimentadas com as dietas CS ou PS apresentaram boa resposta à indução hormonal, enquanto que nas fêmeas do tratamento LS esta resposta não foi satisfatória. Já no experimento 2, tomando como base a dieta CS e substituindo a farinha de carne e ossos por farelo de soja, verificouse que peixes alimentados com a dieta CS70

Tabela II. Desempenho zootécnico das fêmeas reprodutoras de jundiá até a $10^{a}$ semana de alimentação. (Performance of the reproductive jundiá females at the $10^{\mathrm{a}}$ feeding week).

\begin{tabular}{|c|c|c|c|c|}
\hline \multirow[t]{2}{*}{ Variáveis } & \multicolumn{3}{|c|}{ Experimento 1} & \multirow[b]{2}{*}{$d p r$} \\
\hline & CS & PS & LS & \\
\hline Peso inicial (g) & 767,5 & 727,5 & 757,5 & 165,3 \\
\hline Peso final $(g)$ & $1187,5^{\mathrm{a}}$ & $1037,5^{\mathrm{ab}}$ & $900,0^{\mathrm{b}}$ & 74,3 \\
\hline Fator de condição & $1,8^{\mathrm{a}}$ & $1,5^{\mathrm{ab}}$ & $1,3^{\mathrm{b}}$ & 0,2 \\
\hline \multirow[t]{2}{*}{ Ganho em peso $(\mathrm{g})$} & $420,0^{a}$ & $\begin{array}{c}310,0^{a} \\
\text { xperimentc }\end{array}$ & $142,5^{\mathrm{b}}$ & 74,3 \\
\hline & cso & CS35 & CS70 & $\mathrm{dpr}$ \\
\hline Peso inicial $(\mathrm{g})^{1}$ & 691,5 & 788,8 & 558,0 & 182,8 \\
\hline Peso final ajustado para PI $(\mathrm{g})^{1}$ & 844,8 & 901,0 & 812,9 & 217,3 \\
\hline Fator de condição ajustado para $\mathrm{Pl}^{1}$ & 0,9 & 1,0 & 0,9 & 0,1 \\
\hline Ganho em peso ajustado para PI $(\mathrm{g})^{1}$ & 166,9 & 223,2 & 135,1 & 96,2 \\
\hline
\end{tabular}

${ }^{a b}$ Médias seguidas de letras diferentes, na linha, diferem estatisticamente entre si $(p<0,05)$ pelo teste de Tukey. dpr: desvio padrão residual.

Tratamentos: $\mathrm{CS}=$ Farinha de carne e ossos + farelo de soja; $\mathrm{PS}=$ Farinha de peixe + farelo de soja; $\mathrm{LS}=$ Levedura de cana + farelo de soja; CS0, CS35 e CS70 indicam, respectivamente, 0, 35 e $70 \%$ de substituição de farinha de carne e ossos por farelo de soja.

${ }^{1}$ Não significativo $(p>0,05)$. 
PARRA ETAL.

Tabela III. Desenvolvimento ovocitário e embrionário de fêmeas de jundiá alimentadas com fontes protéicas (experimento 1) ou níveis de farelo de soja (experimento 2). (Ovocitic and embrionary development of jundiá females fed with protein sources (trial 1) or soybean meal levels (trial 2)).

\begin{tabular}{|c|c|c|c|c|c|c|c|c|}
\hline & \multicolumn{3}{|c|}{ Experimento 1} & \multicolumn{5}{|c|}{ Experimento 2} \\
\hline & CS & OS & LS & dpr & CSO & CS35 & $\mathrm{CS} 70^{1}$ & dpr \\
\hline & \multicolumn{8}{|c|}{ Ovócitos (não-fecundados) } \\
\hline $\mathrm{DOv}(\mathrm{mm})$ & $0,9^{b}$ & $1,0^{\mathrm{b}}$ & $1,2^{\mathrm{a}}$ & 0,1 & $1,5^{\mathrm{A}}$ & $1,4^{\mathrm{A}}$ & $1,0^{B}$ & 0,1 \\
\hline \multirow[t]{2}{*}{$\mathrm{AOv}\left(\mathrm{mm}^{2}\right)$} & $0,7^{\mathrm{b}}$ & $0,8^{\mathrm{ab}}$ & $1,0^{\mathrm{a}}$ & 0,2 & $1,8^{A}$ & $1,6^{\mathrm{A}}$ & $0,9^{\mathrm{B}}$ & 0,3 \\
\hline & \multicolumn{8}{|c|}{ Ovos (24 horas pós-fecundação) } \\
\hline $\mathrm{DO}(\mathrm{mm})$ & 1,6 & 1,6 & 1,5 & 0,2 & $1,6^{\mathrm{A}}$ & $1,4^{\mathrm{B}}$ & - & 0,1 \\
\hline $\mathrm{AO}\left(\mathrm{mm}^{2}\right)$ & 1,5 & 1,5 & 1,3 & 0,3 & $1,4^{\mathrm{A}}$ & $1,1^{\mathrm{B}}$ & - & 0,1 \\
\hline DSV (mm) & $1,0^{\mathrm{a}}$ & $0,9^{a b}$ & $0,8^{b}$ & 0,1 & 1,0 & 0,9 & - & 0,1 \\
\hline ASV $\left(\mathrm{mm}^{2}\right)$ & 0,7 & 0,7 & 0,6 & 0,1 & 0,5 & 0,5 & - & 0,1 \\
\hline
\end{tabular}

Médias do mesmo experimento seguidas de letras diferentes, na linha, diferem significativamente $(p<0,05)$ pelo teste de Tukey. dpr: desvio padrão residual.

Tratamentos: CS= Farinha de carne e ossos + farelo de soja; PS= Farinha de peixe + farelo de soja; LS= Levedura de cana + farelo de soja; CS0, CS35 e CS70 indicam, respectivamente, 0, 35 e $70 \%$ de substituição de farinha de carne e ossos por farelo de soja.

DOv: Diâmetro do ovócito; AOv: Área do ovócito; DO: diâmetro do ovo; AO: área do ovo; DSV: diâmetro do saco vitelino; ASV: área do saco vitelino.

${ }^{1}$ As fêmeas do tratamento CS70 não desovaram.

não responderam à desova. Este problema pode estar relacionado à grande quantidade de farelo de soja, o que teria levado as fêmeas reprodutoras a uma falha na preparação para a reprodução, provavelmente pela presença de fatores antinutricionais (Moyano et al., 1992). Inibidores de protease, proteínas antigênicas e lectinas presentes no farelo de soja afetam a utilização da proteína, o que pode afetar o desenvolvimento gonadal (incorporação de nutrientes) destas fêmeas (Francis et al., 2001).

A taxa de fecundação não diferiu entre os tratamentos avaliados em nenhum dos experimentos. A fecundação média do experimento 1 foi de $82,1 \%$, e de $81,3 \%$ para o experimento 2. Estes valores são considerados adequados para a espécie, sendo consideradas baixas aquelas taxas menores que 70-80\% (Silva, 2004).

A taxa de fecundação da truta arco-íris (Oncorhynchus mykiss) foi significativa- mente maior nas fêmeas alimentadas com fontes de origem animal (farinha de peixe e farinha de carne e ossos) que aquelas alimentadas com fontes vegetais (farelo de soja, soja integral tostada ou glúten de milho) (Pereira et al., 1998). Os autores atribuem este resultado não somente a composição dos ingredientes utilizados, mas também à menor palatabilidade das dietas de origem vegetal, o que ocasionou redução no consumo.

O tamanho dos ovócitos (diâmetro e área) foi significativamente afetado pelo nível de inclusão de farelo de soja (tabela III). O aquecimento do farelo de soja por menos de 20 minutos ou mais de 30 minutos resulta em aumento de ovócitos pequenos, o que leva a menores taxas de fecundidade e eclosão (Adewumi, 2006). Isto ocorre porque em aquecimentos por menos de $20 \mathrm{mi}-$ nutos boa parte dos fatores antinutricionais não é desativado, já acima de 30 minutos

Archivos de zootecnia vol. 59, núm. 226, p. 260. 


\section{FONTES PROTÉICAS E DESEMPENHO REPRODUTIVO DE FÊMEAS DE JUNDIÁ}

ocorre superaquecimento do farelo e perda de aminoácidos essenciais, principalmente lisina (Tacon, 1997).

Os parâmetros morfométricos representam o estado de desenvolvimento de ovos e larvas (Kjorsvik, 1994). No experimento 1 , às 24 horas pós-fecundação, o tamanho do ovo (diâmetro e área) e a área do saco vitelino não diferiram entre as fontes protéicas. Entretanto, o diâmetro do saco vitelino(DSV) não diferiu entre os tratamentos CS e PS, mas foi superior à dieta LS (tabela III). Isto pode indicar que houve maior produção de vitelogenina nos peixes alimentados com fontes de origem animal em relação ao tratamento LS. A produção de vitelogenina e sua deposição no saco vitelínico são importantes para o desenvolvimento do ovócito e subseqüente sobrevivência do embrião e da larva (Mommsen e Walsh, 1988; Khan et al., 2005). No experimento 2, o desenvolvimento embrionário no tratamento CS0 foi superior ao tratamento CS35, corroborando os resultados obtidos no experimento 1 (tabela III).

Adewumi (2006) alimentou reprodutores de catfish africano (Clarias gariepinus) com dietas contendo farelo de soja com diferentes tempos de aquecimento $(0$ a 30 minutos, além de uma dieta controle com farinha de peixe), e observou que o efeito da dieta na qualidade, crescimento e maturação

Tabela IV. Desenvolvimento das larvas de jundiá (antes da absorção do saco vitelino) obtidas de fêmeas alimentadas com diferentes fontes protéicas (experimento 1) ou níveis de farelo de soja (experimento 2). (Development of jundiá larvae (before yolke salk absortion) obtained of females fed with different protein sources (trial 1) or soybean meal levels (trial 2)).

\begin{tabular}{|c|c|c|c|c|c|c|c|}
\hline \multirow[t]{2}{*}{ Variáveis } & \multicolumn{3}{|c|}{ Experimento 1} & \multirow[b]{2}{*}{$d p r$} & \multicolumn{3}{|c|}{ Experimento $2^{1}$} \\
\hline & CS & PS & LS & & CSO & CS35 & $d p r$ \\
\hline \multicolumn{8}{|l|}{12 horas } \\
\hline $\mathrm{CT}(\mathrm{mm})$ & $5,1^{a}$ & $4,7^{b}$ & $4,7^{\mathrm{b}}$ & 0,2 & 4,2 & 4,2 & 0,2 \\
\hline $\mathrm{AL}\left(\mathrm{mm}^{2}\right)$ & $4,3^{\mathrm{a}}$ & $3,8^{\mathrm{ab}}$ & $3,5^{b}$ & 0,5 & 2,8 & 2,8 & 0,2 \\
\hline $\operatorname{ASV}\left(\mathrm{mm}^{2}\right)$ & $0,8^{\mathrm{a}}$ & $0,6^{b}$ & $0,6^{b}$ & 0,1 & 0,5 & 0,5 & 0,1 \\
\hline \multicolumn{8}{|l|}{24 horas } \\
\hline $\mathrm{CT}(\mathrm{mm})$ & 5,1 & 5,2 & 5,2 & 0,3 & 4,2 & 4,2 & 0,2 \\
\hline $\mathrm{AL}\left(\mathrm{mm}^{2}\right)$ & 4,0 & 4,1 & 4,2 & 0,5 & 2,7 & 2,7 & 0,3 \\
\hline $\operatorname{ASV}\left(\mathrm{mm}^{2}\right)$ & 0,6 & 0,6 & 0,5 & 0,1 & 0,5 & 0,5 & 0,1 \\
\hline \multicolumn{8}{|l|}{36 horas } \\
\hline $\mathrm{CT}(\mathrm{mm})$ & 5,3 & 5,6 & 5,3 & 0,5 & 4,9 & 4,9 & 0,3 \\
\hline $\mathrm{AL}\left(\mathrm{mm}^{2}\right)$ & 4,7 & 5,1 & 4,9 & 0,8 & 3,8 & 3,8 & 0,4 \\
\hline ASV $\left(\mathrm{mm}^{2}\right)$ & $0,5^{\mathrm{a}}$ & $0,4^{\mathrm{ab}}$ & $0,3^{b}$ & 0,1 & 0,4 & 0,4 & 0,1 \\
\hline \multicolumn{8}{|l|}{48 horas } \\
\hline $\mathrm{CT}(\mathrm{mm})$ & $5,9^{\mathrm{a}}$ & $5,7^{\mathrm{ab}}$ & $5,4^{b}$ & 0,2 & 5,3 & 5,3 & 0,2 \\
\hline $\mathrm{AL}\left(\mathrm{mm}^{2}\right)$ & 5,1 & 5,1 & 5,3 & 0,7 & 4,5 & 4,5 & 0,4 \\
\hline ASV $\left(\mathrm{mm}^{2}\right)$ & 0,3 & 0,3 & 0,3 & 0,1 & 0,2 & 0,2 & 0,1 \\
\hline
\end{tabular}

Médias do mesmo experimento seguidas de letras diferentes, na mesma linha, diferem estatisticamente $(p<0,05)$ pelo teste de Tukey. dpr: desvio padrão residual.

Tratamentos: $\mathrm{CS}=$ Farinha de carne e ossos + farelo de soja; PS= Farinha de peixe + farelo de soja; $\mathrm{LS}=$ Levedura de cana + farelo de soja; CS0, CS35 e CS70 indicam, respectivamente, 0, 35 e 70\% de substituição de farinha de carne e ossos por farelo de soja.

Variáveis: $\mathrm{CT}=$ comprimento total da larva; $\mathrm{AL}=$ área da larva; $\mathrm{ASV}=$ área do saco vitelino.

${ }^{1}$ As fêmeas do tratamento CS70 não desovaram. 
PARRA ET AL.

dos ovócitos foi idêntico ao resultado obtido para crescimento. $\mathrm{O}$ autor concluiu que os reprodutores que cresceram mais durante o experimento foram os que alcançaram maturação mais rapidamente.

As larvas obtidas no tratamento CS (experimento 1) apresentaram maior comprimento total $(\mathrm{CT})$, área da larva $(\mathrm{AL})$ e área de saco vitelino(ASV) que os demais tratamentos, até as 12 horas após eclosão (tabela IV). Com o passar do tempo, essas diferenças não foram observadas, exceto para ASV às 36 horas e $\mathrm{CT}$ às 48 horas. No experimento 2 , nenhuma diferença significativa foi observada entre os tratamentos (tabela IV).
Além de sua importância estrutural, funcional e energética, a proteína tem papel fundamental na fertilização e no desenvolvimento normal do embrião. Segundo Fernández-Palacios et al. (1997), a incorporação de farinha de lulas em substituição à farinha de peixe resulta em efeito positivo na reprodução de gilthead seabream, sendo atribuído ao melhor perfil de aminoácidos e maior digestibilidade da proteína naquela fonte. Para a mesma espécie, uma dieta balanceada em aminoácidos essenciais promove aumento da produção de vitelogenina, que é o principal precursor na formação do saco vitelino em peixes (Izquierdo et al., 2001).

Tabela $\boldsymbol{V}$. Desempenho das pós-larvas de jundiá obtidas de fêmeas alimentadas com diferentes fontes protéicas (experimento 1) ou níveis de farelo de soja (experimento 2). (Performance of the jundiá post-larvae obtained of females fed with different protein sources (trial 1) or soybean meal levels (trial 2)).

\begin{tabular}{|c|c|c|c|c|c|c|c|}
\hline \multirow[t]{2}{*}{ Variáveis } & \multicolumn{3}{|c|}{ Experimento 1} & \multicolumn{4}{|c|}{ Experimento $2^{1}$} \\
\hline & CS & PS & LS & $\mathrm{dpr}$ & cso & CS35 & $d p r$ \\
\hline \multicolumn{8}{|l|}{ Inicial } \\
\hline PM (mg) & 1,1 & 1,2 & 1,6 & 0,5 & $1,9^{A}$ & $1,2^{\mathrm{B}}$ & 0,2 \\
\hline $\mathrm{CT}(\mathrm{mm})$ & 5,8 & 5,7 & 5,7 & 0,2 & $5,6^{A}$ & $5,5^{\mathrm{A}}$ & 0,4 \\
\hline $\operatorname{APL}\left(\mathrm{mm}^{2}\right)$ & $5,1^{\mathrm{ab}}$ & $5,3^{\mathrm{a}}$ & $4,7^{b}$ & 0,5 & $5,7^{A}$ & $3,9^{\mathrm{B}}$ & 0,5 \\
\hline \multicolumn{8}{|l|}{7 dias } \\
\hline PM (mg) & 5,4 & 6,4 & 5,3 & 1,3 & $6,8^{A}$ & $5,9^{A}$ & 0,6 \\
\hline $\mathrm{CT}(\mathrm{mm})$ & $8,4^{\mathrm{ab}}$ & $8,6^{a}$ & $8,0^{\mathrm{b}}$ & 0,3 & $8,5^{\mathrm{A}}$ & $7,8^{\mathrm{B}}$ & 0,3 \\
\hline SOB (\%) & 92,7 & 96,9 & 98,9 & 7,5 & $96,4^{\mathrm{A}}$ & $62,0^{\mathrm{B}}$ & 2,2 \\
\hline $\mathrm{APL}\left(\mathrm{mm}^{2}\right)$ & $12,7^{\mathrm{ab}}$ & $13,6^{a}$ & $11,9^{b}$ & 1,1 & $16,1^{\mathrm{A}}$ & $13,0^{B}$ & 1,0 \\
\hline TCE $\left(\%\right.$. dia $\left.^{-1}\right)$ & $22,1^{\mathrm{ab}}$ & $23,4^{a}$ & $17,1^{\mathrm{b}}$ & 3,9 & $18,2^{\mathrm{B}}$ & $22,7^{\mathrm{A}}$ & 1,3 \\
\hline \multicolumn{8}{|l|}{14 dias } \\
\hline PM (mg) & $10,5^{b}$ & $13,7^{a}$ & $14,8^{a}$ & 1,9 & $32,1^{\mathrm{A}}$ & $26,4^{\mathrm{A}}$ & 3,4 \\
\hline $\mathrm{CT}(\mathrm{mm})$ & 10,4 & 10,6 & 10,4 & 0,4 & $13,6^{\mathrm{A}}$ & $11,8^{\mathrm{B}}$ & 0,6 \\
\hline SOB (\%) & 59,8 & 63,6 & 73,3 & 12,7 & $88,1^{\mathrm{A}}$ & $54,7^{\mathrm{B}}$ & 2,2 \\
\hline $\mathrm{APL}\left(\mathrm{mm}^{2}\right)$ & 14,7 & 16,7 & 17,6 & 1,9 & $42,1^{\mathrm{A}}$ & $34,0^{\mathrm{B}}$ & 4,0 \\
\hline $\operatorname{TCE}\left(\% \cdot \mathrm{dia}^{-1}\right)$ & 16,0 & 17,1 & 15,8 & 1,1 & $20,2^{A}$ & $22,0^{\mathrm{A}}$ & 0,9 \\
\hline
\end{tabular}

Médias seguidas de letras diferentes, na mesma linha, diferem estatisticamente $(p<0,05)$ pelo teste de Tukey (experimento 1) ou teste "t" (experimento 2).

Tratamentos: $\mathrm{CS}=$ Farinha de carne e ossos + farelo de soja; $P S=$ Farinha de peixe + farelo de soja; $\mathrm{LS}=$ Levedura de cana + farelo de soja. CS0, CS35 e CS70 indicam, respectivamente, 0, 35 e $70 \%$ de substituição de farinha de carne e ossos por farelo de soja.

Variáveis: $\mathrm{PM}=$ peso médio; $\mathrm{CT}=$ comprimento total; $\mathrm{SOB}=$ sobrevivência; $\mathrm{APL}=$ área da pós-larva; $T \mathrm{TE}=$ taxa de crescimento específico.

${ }^{1}$ As fêmeas do tratamento CS70 não desovaram.

Archivos de zootecnia vol. 59, núm. 226, p. 262. 


\section{FONTES PROTÉICAS E DESEMPENHO REPRODUTIVO DE FÊMEAS DE JUNDIÁ}

No experimento 1, as pós-larvas oriundas dos tratamentos CS e PS não diferiram significativamente até os 7 dias, apresentando maior comprimento total, área e taxa de crescimento específico que as pós-larvas do tratamento LS (tabela V). Já aos 14 dias, o tratamento CS apresentou o menor peso médio, sendo que as demais variáveis não difeririam significativamente. No experimento 2, o desenvolvimento das pós-larvas foi superior no tratamento $\mathrm{CS} 0$, para a maioria das variáveis (tabela V).

Poucos estudos têm sido conduzidos visando avaliar o efeito da nutrição dos reprodutores sobre a qualidade das póslarvas, sendo a maioria voltada para o efeito dos lipídios e ácidos graxos (Duray et al., 1994; Fernández-Palacios et al., 1998; Izquierdo et al., 2001). No que diz respeito à proteína, sabe-se que o histórico nutricional de fêmeas de tilápia (Oreochromis niloticus), mais precisamente o nível de proteína da dieta e a disponibilidade de aminoácidos, influencia a viabilidade das pós-larvas, sendo que em níveis de proteína abaixo de $20 \%$ os ovos nem chegam a ser fertilizados (Gunasekera et al., 1996b). A utilização de farinha de peixe ou farinha de carne e ossos na dieta de reprodutores de Clarias macrocephalus não influencia na sobrevivência, comprimento total e peso médio das larvas (Santiago e Gonzal, 1997).

Muitos autores destacam a importância da qualidade da proteína na nutrição dos reprodutores e os efeitos na sua progênie (Fernández-Palacios et al., 1997; Santiago e Gonzal, 1997; Izquierdo et al., 2001). Entre-

\section{BIBLIOGRAFIA}

Adewumi, A.A. 2006. The growth and gonadal maturation of the african catfish, Clarias gariepinus (Burchell) broodstock fed differently heated soybean-based diets. Aquacult. Nutr., 12: 267-274.

Baldisserotto, B. 2004. Biologia do jundiá. Em: B. Baldisserotto e J. Radünz Neto (Eds.). Criação de jundiá. Editora UFSM. Santa Maria. RS. pp:67-72. tanto, poucos são os trabalhos que trazem dados conclusivos acerca deste nutriente e sua relação com a qualidade reprodutiva dos peixes, sendo concentrados a poucas espécies. Novos estudos devem ser conduzidos visando avaliar as respostas metabólicas, hormonais e reprodutivas dos peixes em função qualidade protéica da dieta, pois o conhecimento da nutrição dos reprodutores reflete-se diretamente na quantidade e qualidade da progênie, influenciando toda a cadeia produtiva.

\section{CONCLUSÃO}

A utilização de farinha de carne e ossos em combinação com farelo de soja como fontes protéicas apresenta-se como boa opção na alimentação de fêmeas reprodutoras de jundiá. A inclusão de $60 \%$ de farelo de soja em dietas para fêmeas de jundiá prejudica o desempenho reprodutivo e a viabilidade dos ovos.

\section{AGRADECIMENTOS}

Os autores agradecem ao SEAP/MCT/ Fundo setorial Agronegócio/Fundo CT Hidro/FINEP (Ação transversal 3602/05), pelo auxílio financeiro; ao Núcleo de Análise de Imagens Biológicas (NAIMB). Laboratório de Ictiopatologia, do Departamento de Biologia e Química da Universidade Regional do Noroeste do Rio Grande do Sul UNIJUI, pela realização das análises morfométricas; e às empresas Vitagri Nutrição Animal, Zillo Lorenzetti e Cooperativa Tritícola Santiaguense, pelo fornecimento de ingredientes para elaboração das dietas.

Bromage, N., Jones, J., Randall, C., Thrush, M. Davies, B., Springate, J., Duston, J. and Baker, G. 1992. Broodstock management, fecundity, egg quality and the timing of egg production in the rainbow trout (Oncorhynchus mykiss). Aquaculture, 100: 141-166.

Brooks, S., Tyler, C.R. and Sumpter, J.P. 1997. Egg quality in fish: what makes a good egg?. Rev. 
PARRA ET AL.

Fish. Biol. Fisher., 7: 387-416.

Campabadal, C. y Celis, A. 1996. Factores que afectan la calidad de los alimentos acuícolas. En: L.E.C. Suárez, D.R. Marie y R.M. Alfaro (Eds.). Memorias del Tercer Simposium Internacional de Nutrición Acuícola, 11-13 noviembre, 1996. Universidad Autónoma de Nuevo León. Monterrey. Nuevo León. México. pp. 523-540.

Carneiro, P.C.F. 2004. A produção de jundiá em cativeiro. Em: B. Baldisserotto e J. Radünz Neto (Eds.). Criação de jundiá. Editora UFSM. Santa Maria. RS. pp: 117-141.

Coldebella, I. e Radünz Neto, J. 2002. Farelo de soja na alimentação de alevinos de jundiá (Rhamdia quelen). Cienc. Rural, 32: 499-503.

Duray, M., Kohno, J. and Pascual, J. 1994. The effect of lipid enriched broodstock diets on spawning and on egg and larval quality of hatchery-bred rabbitfish (Siganus guttatus). Philipp. Sci., 31: 42-57.

Eiras, C., Takemoto, R.M. e Pavanelli, G.C. 2000. Métodos de estudo e técnicas laboratoriais em parasitologia de peixes. EDUEM. Maringá. PR.

Fernández-Palacios, H., Izquierdo, M., Robaina, L., Valencia, A., Salhi, M. and Montero, D. 1997. The effect of dietary protein and lipid from squid and fish meals on egg quality of broodstock for Gilthead seabream (Sparus aurata). Aquaculture, 148: 233-246.

Fernández-Palacios, H., Izquierdo, M.S., Gonzalez, M., Robaina, L. and Valencia, A. 1998. Combined effect of dietary $\alpha$-tocopherol and n-3 HUFA on egg quality of gilthead seabream broodstock (Sparus aurata). Aquaculture, 161: 475-476.

Francis, G., Makkar, H.P.S. and Becker, K. 2001. Antinutritional factors present in plant-derived alternate fish feed ingredients and their effects in fish. Aquaculture, 199: 197-227.

Gunasekera, R.M., Shim, K.F. and Lam, T.J. 1996a. Influence of dietary protein content on the distribution of amino acids in oocytes, serum and muscle of Nile tilapia, Oreochromis niloticus (L.). Aquaculture, 152: 205-221.

Gunasekera, R.M., Shim, K.F. and Lam, T.J. 1996b. Influence of protein content of broodstock diets on larval quality and performance in Nile tilapia, Oreochromis niloticus (L.). Aquaculture, 146: 245-259.

Izquierdo, M.S., Fernández-Palacios, H. and Tacon, A.G.J. 2001. Effect of broodstock nutrition on reproductive performance of fish. Aquaculture, 197: 25-42.

Khan, M.A., Jafri, A.K. and Chadha, N.K. 2005. Effects of varying dietary protein levels on growth, reproductive performance, body and egg composition of rohu, Labeo rohita (Hamilton). Aquacult. Nutr., 11: 11-17.

Kim, M.K., Özkök, E. and Han, I.K. 1997. Effect of soybean meal and full-fat soybean for fish meal replacement on the growth performance of carp grower. Korean J. Anim. Nutr. Feed., 21: 503-510.

Kjorsvik, E. 1994. Egg quality in wild and broodstock cod Gadus morhua L. J. World Aquacult. Soc., 25: 22-31.

Lazzari, R., Radünz Neto, J., Veiverberg, C.A., Bergamin, G.T., Correia, V. e Pedron, F.A. 2007. Alimentação do jundiá (Rhamdia quelen, Heptateridae) com ingredientes protéicos. Arch. Zootec., 56: 115-123.

Lovell, T. 1988. Nutrition and feeding of fish. Van Nostrand and Reinhold. New York.

Moyano, F.J., Cradenete, G. and Higuera, M.D.L. 1992. Nutritive value of diets containing a high percentage of vegetable proteins for trout, Oncorhynchus mykiss. Aquat. Living Resour., 5: 21-39.

Mommsen, T. and Walsh, P. 1988. Vitellogenesis and oocyte assembly. In: W.S. Hoar and D.J. Randall (Eds.). Fish physiology. The physiology of developing fish: eggs and larvae. Academic Press. New York. pp: 347-406.

Mohsen, A.A. and Lovell, R.T. 1990. Partial substitution of soybean meal with animal protein sources in the diets for channel catfish. Aquaculture, 90: 303-311.

Pereira, J.O.B., Reis-Henriques, M.A., Sanchez, J.L. and Costa, J.M. 1998. Effect of protein source on the reproductive performance of female rainbow trout, Oncorhynchus mykiss (Walbaum). Aquac. Res., 29: 751-760.

Pezzato, L.E. 1995. Alimentos convencionais e não convencionais disponíveis para a indústria de nutrição de peixes no Brasil. Em: Simpósio internacional sobre nutrição de peixes e crustáceos. Colégio Brasileiro de Nutrição Animal. Campinas. SP.

Pezzato, L.E. 1996. Tecnologia de processamento de dietas, alimentos e alimentação de organismos aquáticos. UNESP. Jaboticabal. SP. 


\section{FONTES PROTÉICAS E DESEMPENHO REPRODUTIVO DE FÊMEAS DE JUNDIÁ}

Piaia, R. e Radünz Neto, J. 1997. Efeito de níveis crescentes de levedura de álcool em rações contendo fígado bovino sobre a performance de larvas de jundiá (Rhamdia quelen). Cienc. Rural, 27: 313-317.

Piaia, R., Uliana, O., Filipetto, J.E.S. e Radünz Neto, J. 1997. Alimentação de larvas de jundiá (Rhamdia quelen), com dietas artificiais. Rev. Cienc. Natura, 19: 119-131.

Robinson, E.H. and Li, M.H. 2002. Channel catfish, Ictalurus punctatus. In: C.D. Webster and C.E. Lim (Eds.). Nutrient requirements and feeding of finfish for aquaculture. CABI Publishing. London. pp: 293-318.

Salhi, M., Bessonart, M., Chediak, G., Bellagamba, M. and Carnevia, D. 2004. Growth, feed utilization and body composition of black catfish, Rhamdia quelen, fry fed diets containing different protein and energy levels. Aquaculture, 231: 435-444.

Santiago, C.B. and Gonzal, A.C. 1997. Growth and reproductive performance of the Asian catfish
Clarias macrocephalus (Gunther) fed artificial diets. J. Appl. Ichthyol., 13: 37-40.

SAS. 1997. Statistical Analysis System. User's guide. Version $6.08,4^{\text {th }}$ ed. SAS Institute Inc. North Caroline.

Silva, L.V.F. 2004. Incubação e larvicultura. Em: B. Baldisserotto e J. Radünz Neto (Eds.). Criação de jundiá. Editora UFSM, Santa Maria, RS. pp: 107-116.

Silva, L.V.F., Radünz Neto, J. e Baldisserotto, B. 2004. Reprodução de jundiá. Em: B. Baldisserotto e J. Radünz Neto (Eds.). Criação de Jundiá. Editora UFSM. Santa Maria. RS. pp: 95-106.

Tacon, A.G.J. 1997. Fishmeal replacers: Review of antinutrients within oilseeds and pulses - A limiting factor for the aquafeed Green Revolution? In: A.G.J. Tacon and B. Basurco B. (Eds.). Feeding tomorrow's fish. Workshop of the CIHEAM Network on Technology of Aquaculture in the Mediterranean (TECAM). CIHEAM-IAMZ. Zaragoza. pp.153-182. 